\title{
₹USGS
}

\section{Reserve Growth in Oil Fields of West Siberian Basin, Russia}

\author{
Mahendra K. Verma ${ }^{1}$ and Gregory F. Ulmishek ${ }^{2}$
}

\begin{abstract}
Although reserve (or field) growth has proven to be an important factor contributing to new reserves in mature petroleum basins, it is still a poorly understood phenomenon. Limited studies show that the magnitude of reserve growth is controlled by several major factors, including (1) the reserve booking and reporting requirements in each country, (2) improvements in reservoir characterization and simulation, (3) application of enhanced oil recovery techniques, and (4) the discovery of new and extensions of known pools in discovered fields. Various combinations of these factors can affect the estimates of proven reserves in particular fields and may dictate repeated estimations of reserves during a field's life. This study explores the reserve growth in the 42 largest oil fields in the West Siberian Basin, which contain about 55 percent of the basin’s total oil reserves.
\end{abstract}

The West Siberian Basin occupies a vast swampy plain between the Ural Mountains and the Yenisey River, and extends offshore into the Kara Sea; it is the richest petroleum province in Russia. About 600 oil and gas fields with original reserves of 144 billion barrels of oil (BBO) and more than 1,200 trillion cubic feet of gas (TCFG) have been 
discovered. The principal oil reserves and most of the oil fields are in the southern half of the basin, whereas the northern half contains mainly gas reserves.

Sedimentary strata in the basin consist of Upper Triassic through Tertiary clastic rocks. Most oil is produced from Neocomian (Lower Cretaceous) marine to deltaic sandstone reservoirs, although substantial oil reserves are also in the marine Upper Jurassic and continental to paralic Lower to Middle Jurassic sequences. The majority of oil fields are in structural traps, which are gentle, platform-type anticlines with closures ranging from several tens of meters to as much as 150 meters (490 feet). Fields producing from stratigraphic traps are generally smaller except for the giant Talin field which contains oil in Jurassic river-valley sandstones. Principal source rocks are organic-rich marine shales of the Volgian (uppermost Jurassic) Bazhenov Formation, which is 30-50 m (98- 164 feet) thick. Bazhenov-derived oils are mostly of medium gravity, and contain 0.8-1.3 percent sulfur and 2-5 percent paraffin. Oils in the Lower to Middle Jurassic clastics were sourced from lacustrine and estuarine shales of the Toarcian Togur Bed. These oils are medium to low gravity, with low sulfur (less than 0.25 percent) and high paraffin (commonly to 10 percent) contents.

Among the 42 fields analyzed for reserve growth, 30 fields are located in the Middle Ob region, which includes the Samotlor field with reserves of more than $25 \mathrm{BBO}$ and the Fedorov field with reserves of about 5 BBO. Data used in the study include year of discovery, year of first production, annual and cumulative production, and remaining reserves reported by Russian reserve categories $\left(A+B+C_{1}\right.$ and $\left.C_{2}\right)$ in January of each 
year. Correlation of these Russian resource categories to U.S. categories of the Society of Petroleum Engineers classification is complex and somewhat uncertain.

Reserve growth in oil fields of West Siberia was calculated using a newly developed Group Growth method, which requires that the total reserve (proven reserve plus cumulative production) of individual fields with an equal length of reserve record be added together starting with discovery year or the first production year. Then the annual growth factor (AGF), which is the ratio of total reserves of two consecutive years, is calculated for all years. Once AGFs have been calculated, the cumulative growth factor (CGF) is calculated by multiplying the AGFs of all the previous years. The CGF data are used to develop reserve growth models.

The West Siberian oil fields show a 13-fold reserve growth 20 years after the discovery year and only about a 2-fold growth after the first production year. This difference is attributed to extensive exploration and field delineation activities between the discovery and the first production years. Because of uncertainty in the length of evaluation time and in reported reserves during this initial period, reserve growth based on the first production year is more reliable for model development. However, reserve growth models based both on discovery year and first production year show rapid growth in the first few years and slower growth in the following years. In contrast, the reserve growth patterns for the conterminous United States and offshore Gulf of Mexico show a steady reserve increase throughout the productive lives of the fields. The different reserve booking requirements and the lack of capital investment for improved reservoir management and production 
technologies in West Siberian fields relative to U.S. fields are the probable causes for the difference in growth patterns.

Reserve growth models based on the first production year predict that the reserve growth potential in the 42 largest oil fields of West Siberia over a five-year period (1998-2003) ranges from 270-330 million barrels or 0.34-0.42 percent per year. For a similar five-year period (1996-2001), models for the conterminous United States predict a growth of 0.540.75 percent per year.

This abstract presents the contents of a poster prepared for the AAPG Hedberg Research Conference on Understanding World Oil Resources, November 12-17, 2006 - Colorado Springs, Colorado. A paper "Reserve Growth in Oil Fields of West Siberian Basin, Russia” was published in Natural Resources Research, v. 12, no. 2, June, 2003.

\footnotetext{
${ }^{1}$ U.S. Geological Survey (USGS), Energy Resources Team, Central Region, Denver Federal Center, P.O., Box 25046, MS 939, Denver, Colorado 80225; email: mverma@usgs.gov

${ }^{2}$ Ex-USGS, now with the Direct Petroleum Exploration, Inc., Denver, Colorado; email: gulmishek@directpetroleum.com
} 